Erratum

\title{
Erratum: Zhao et al. Robust and Efficient Trajectory Replanning Based on Guiding Path for Quadrotor Fast Autonomous Flight. Remote Sens. 2021, 13, 972
}

\author{
Yinghao Zhao ${ }^{1}$, Li Yan ${ }^{1, *}$, Yu Chen ${ }^{1}\left(\mathbb{D}\right.$, Jicheng Dai ${ }^{1}$ and Yuxuan Liu ${ }^{2}$ (D) \\ 1 School of Geodesy and Geomatics, Wuhan University, Wuhan 430079, China; \\ zhaoyinghao@whu.edu.cn (Y.Z.); chenyuphd@whu.edu.cn (Y.C.); daijicheng@whu.edu.cn (J.D.) \\ 2 Institute of Photogrammetry and Remote Sensing, Chinese Academy of Surveying and Mapping, \\ Beijing 100036, China; liuyx@whu.edu.cn \\ * Correspondence: lyan@sgg.whu.edu.cn
}

check for

updates

Citation: Zhao, Y.; Yan, L.; Chen, Y.; Dai, J.; Liu, Y. Erratum: Zhao et al. Robust and Efficient Trajectory Replanning Based on Guiding Path for Quadrotor Fast Autonomous Flight. 2021, 13, 972. Remote Sens. 2021, 13, 2791. https://doi.org/ $10.3390 /$ rs13142791

Received: 19 May 2021

Accepted: 3 July 2021

Published: 16 July 2021

Publisher's Note: MDPI stays neutra with regard to jurisdictional claims in published maps and institutional affiliations.

Copyright: (C) 2021 by the authors Licensee MDPI, Basel, Switzerland. This article is an open access article distributed under the terms and conditions of the Creative Commons Attribution (CC BY) license (https:/ / creativecommons.org/licenses/by/ $4.0 /)$
The authors wish to make the following corrections to this paper [1].

In the original article, there was a mistake in Figure $9 \mathrm{a}, \mathrm{d}$ as published. There are redundant marks that have not been found and deleted before in a and $d$ of Figure 9. In order to ensure the precision of the article, correction is needed for the sake of rigor. The corrected Figure $9 \mathrm{a}, \mathrm{d}$ appears below. The authors apologize for any inconvenience caused and state that the scientific conclusions are unaffected. The original article has been updated.

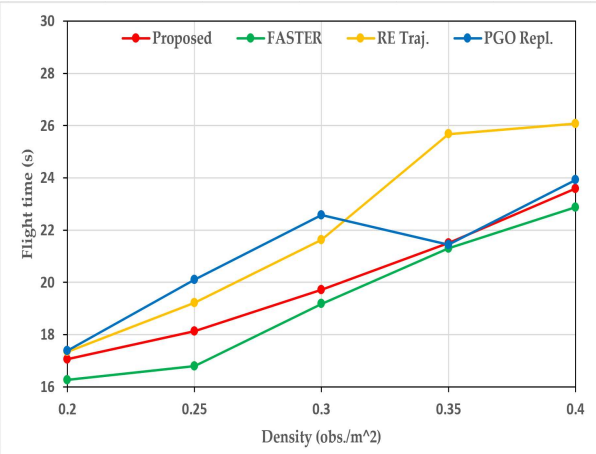

(a) Avg. flight time (s).

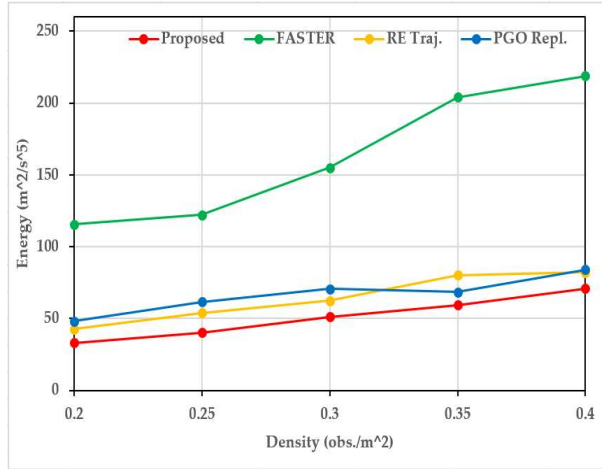

(c) Avg. consumed energy $\left(\mathrm{m}^{2} / \mathrm{s}^{5}\right)$.

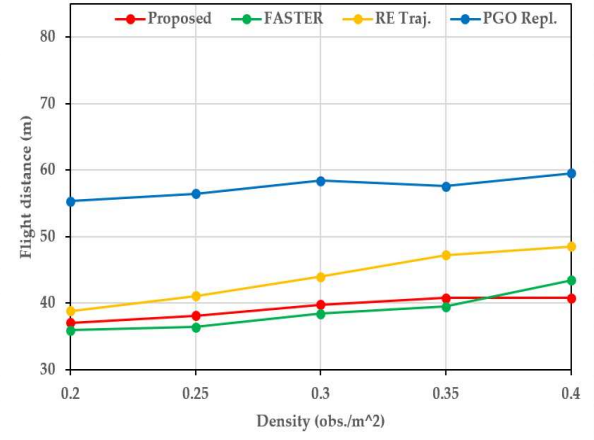

(b) Avg. flight distance (m).

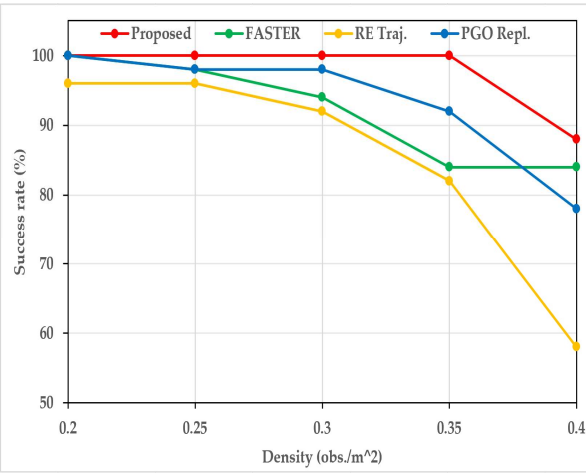

(d) Avg. success rate (\%)
Figure 9. Results of the comparisons between the proposed method and FASTER, RET, PGO in different obstacle densities.

\section{Reference}

1. Zhao, Y.; Yan, L.; Chen, Y.; Dai, J.; Liu, Y. Robust and Efficient Trajectory Replanning Based on Guiding Path for Quadrotor Fast Autonomous Flight. Remote Sens. 2021, 13, 972. [CrossRef] 